\title{
Dinâmica da composição lipídica das fórmulas infantis e suas implicações clínicas
}

\author{
Dynamics of lipid composition of infant formulas and their clinical implications
}

DOI: $10.37111 /$ braspenj.2020353015

Mário Cícero Falcão

\section{Unitermos:}

Lipídeos. Leite Humano. Fórmulas Infantis. Lactente.

\section{Keywords:}

Lipids. Milk, Human. Infant Formula. Infant.

\section{Endereço para correspondência:}

Mário Cícero Falcão

Instituto da Criança Av. Dr. Enéas Carvalho de Aguiar

647, São Paulo, SP, Brasil - CEP 05403-901

E-mail: mario.falcao@hc.fm.usp.br

\section{Submissão}

9 de agosto de 2020

Aceito para publicação

3 de setembro de 2020

\begin{abstract}
RESUMO
No leite humano, destaca-se o papel dos lipídeos como fonte para o crescimento e desenvolvimento adequados do lactente. $\mathrm{O}$ sistema lipídico do leite materno, responsável por aproximadamente $50 \%$ das calorias, é estruturado para o recém-nascido e o lactente. A digestão e absorção do lipídeo são facilitadas pela organização da gordura, pelo tipo de ácido graxo (ácidos palmítico, oleico, linoleico, linolênico, etc.), pela composição dos triglicerídeos e pela lípase estimulada pelos sais biliares. Além disso, o leite contém ácido docosaexaenoico, que permite um ótimo desenvolvimento neurológico e imunológico. Apesar da estrutura lipídica do leite materno ser extremamente complexa, ela deve servir de modelo para a dinâmica da composição lipídica das fórmulas infantis. A adição de ácidos graxos de cadeia longa (ácidos araquidônico e docosaexaenoico) ligados a fosfolipídeos em fórmulas infantis pode contribuir para um melhor desenvolvimento de lactentes, assim como atuar no sistema imunológico e no "imprinting" metabólico, reduzindo o risco de doenças crônicas não transmissíveis. Lactentes recebendo fórmulas com ácido palmítico na posição B-2 apresentam maior contagem de lactobacilos nas fezes, quando comparados aos que recebem fórmulas com ácido palmítico nas posições $\beta-1$ e $\beta-3$, promovendo a manutenção da eubiose intestinal. Lactentes recebendo fórmulas com ácido palmítico ß-2 apresentam saúde óssea similar aos lactentes em aleitamento materno, pois não ocorre perda fecal de cálcio.
\end{abstract}

\section{ABSTRACT}

In human milk, the role of lipids as a source for the adequate growth and development of the infant is highlighted. The lipidic system of breast milk, responsible for approximately $50 \%$ of calories, is structured for the newborn and the infant. Digestion and absorption of lipids are facilitated by the organization of fat, the type of fatty acid (palmitic, oleic, linoleic, linolenic acids, etc.), the composition of triglycerides and the lipase stimulated by bile salts. In addition, milk contains docosahexaenoic acid, which allows optimal neurological and immunological development. Although the lipid structure of breast milk is extremely complex, it should serve as a model for the dynamics of the lipid composition of infant formulas. The addition of long-chain fatty acids (arachidonic and docosahexaenoic acids) linked to phospholipids in infant formulas can contribute to a better development of infants, as well as acting on the immune system and metabolic imprinting, reducing the risk of chronic non-communicable diseases. Infants receiving formulas with palmitic acid in theß-2 position have a higher lactobacillus count in the feces, when compared to those receiving formulas with palmitic acid in the B-1 and B-3 positions, promoting the maintenance of intestinal eubiosis. Infants receiving formulas with $B-2$ palmitic acid present bone health similar to infants breastfeeding, as fecal calcium loss does not occur.

1. Doutor em Pediatria pela Faculdade de Medicina da Universidade de São Paulo. Professor Colaborador do Departamento de Pediatria da Faculdade de Medicina da Universidade de São Paulo. Especialista em Pediatria com área de atuação em Nutrologia Pediátrica pela Sociedade Brasileira de Pediatria. Especialista em Nutrição Parenteral e Enteral pela BRASPEN. Médico da Unidade de Terapia Intensiva Neonatal do Instituto da Criança do Hospital das Clínicas da FMUSP. Editor Associado da Revista Brasileira de Nutrição Clínica. Editor Executivo da Revista Paulista de Pediatria. Coordenador da Equipe Multidisciplinar de Terapia Nutricional (EMTN) do Hospital Santa Catarina, São Paulo. Membro do Departamento de Suporte Nutricional da Sociedade Brasileira de Pediatria. Membro do Departamento de Nutrologia da Sociedade de Pediatria de São Paulo, São Paulo, SP, Brasil. 


\section{INTRODUÇÃO}

Lipídeos são definidos como uma classe de compostos normalmente insolúveis em água, contendo basicamente carbono, hidrogênio e oxigênio. Variam em tamanho e polaridade e abrangem desde triglicerídeos e ésteres hidrofóbicos até fosfolipídeos e cardiolipinas'.

Os lipídeos dietéticos também incluem colesterol e fitoesterol, no entanto, esses compostos se distinguem dos outros lipídeos, pois passam por processos especializados durante a digestão, absorção, transporte, armazenamento e utilização'.

Os triglicerídeos compõem a maior porção dos lipídeos. Eles são compostos por três ácidos graxos (iguais ou diferentes) esterificados em uma molécula de glicerol (Figura 1). Esses ácidos graxos são, em geral, não ramificados e possuem de 4 a 26 carbonos em sua molécula?.

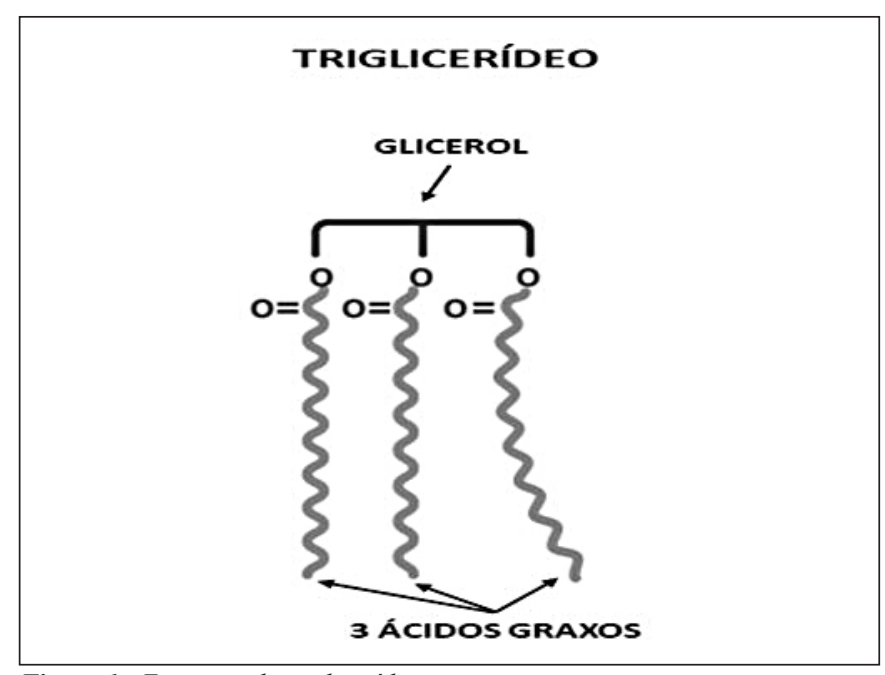

Figura 1 - Estrutura do triglicerídeo.

A maioria dos ácidos graxos de cadeia longa e muito longa está presente em fosfolipídeos das membranas celulares e em tecidos específicos, como cérebro e retina. Os fosfolipídeos contêm grupos polares que os tornam anfipáticos e, portanto, capazes de formarem micelas em meio aquoso'.

No leite humano, destaca-se o papel dos lipídeos como fonte para o crescimento adequado do lactente. $O$ sistema lipídico do leite materno, responsável por aproximadamente $50 \%$ das calorias, é estruturado para o recém-nascido e o lactente. A digestão e absorção do lipídeo são facilitadas pela organização da gordura, pelo tipo de ácido graxo (ácidos palmítico, oleico, linoleico, linolênico, etc.), pela composição dos triglicerídeos e pela lipase estimulada pelos sais biliares. Assim, o leite humano é o alimento de escolha para o lactente, não só pela sua capacidade de promover a digestão e absorção das gorduras, como também em razão das profundas funções metabólicas atribuídas a sua composição ideal de ácidos graxos essenciais e polinsaturados de cadeia longa, principalmente o ácido docosaexaenoico (DHA), que permite um ótimo desenvolvimento neurológico e imunológico².

\section{CLASSIFICAÇÃO DOS LIPÍDEOS}

As características dos ácidos graxos são utilizadas para sua nomenclatura e classificação, conforme descrito a seguir:

- Número de carbonos: ácidos graxos de cadeia curta (até 4 átomos), cadeia média (6 a 12 átomos de carbono), cadeia longa (1 4 a 18 átomos de carbono), cadeia muito longa (a partir de 20 átomos de carbono);

- Número de duplas ligações: saturado (sem duplas ligações) e insaturados (contendo dupla ligação), sendo monoinsaturados (1 dupla ligação) e polinsaturados (2 ou mais duplas ligações) (Figura 2);

- Posição da primeira dupla ligação: identifica-se a posição da primeira dupla ligação contada a partir do radical metil (representada pela letra ômega).

Os lipídeos podem, ainda, ser classificados em simples, compostos e variados:

- Lipídeos simples: ácidos graxos, gorduras neutras (ésteres de ácidos graxos com glicerol, como, por exemplo, os triglicerídeos), ceras (ésteres de ácidos graxos com álcool, como, por exemplo, o colesterol);

- Lipídeos compostos: fosfolipídeos (compostos por ácido fosfórico, ácidos graxos e base nitrogenada), glicolipídeos (compostos por ácidos graxos, monossacarídeo e base nitrogenada), lipoproteína (lipídeo e proteína) (Figura 3);

- Lipídeos variados: esteroides (colesterol, vitamina D e sais biliares), vitaminas A, E e K.

\section{FUNÇÕES DOS LIPÍDEOS}

Em linhas gerais, os lipídeos são fonte de energia com alta densidade calórica, atuam na síntese de hormônios, estruturas celulares, transporte de vitaminas lipossolúveis e fornecem ácidos graxos essenciais (ácidos linoleico e alfa-linolênico) ${ }^{3}$.

O Quadro 1 resume as principais ações dos lipídeos.

\section{ÁCIDOS GRAXOS POLINSATURADOS DE CADEIA LONGA}

Os ácidos graxos polinsaturados são classificados de acordo com a posição da primeira ligação dupla na cadeia carbônica. Duas cadeias são importantes para o metabolismo humano, a cadeia ômega 6, cujos principais representantes são os ácidos linoleico e araquidônico (ARA) e a cadeia ômega 3, que será detalhada a seguir.

A Figura 4 mostra a síntese dos ácidos graxos polinsaturados de cadeia longa ômega 6 e ômega 3. 


\begin{tabular}{|c|c|c|c|c|c|}
\hline \multirow{4}{*}{ 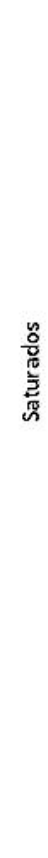 } & 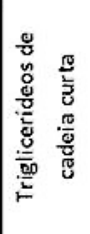 & $\begin{array}{l}\text { Ácido acético C 2:0 } \\
\text { Ácido propiônico C 3:0 }\end{array}$ & \multirow[t]{2}{*}{ 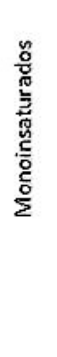 } & \multirow[t]{2}{*}{ 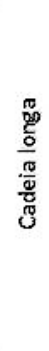 } & \multirow[t]{2}{*}{ Ácido oleico C 18:1- $\omega 9$} \\
\hline & \multirow{2}{*}{ 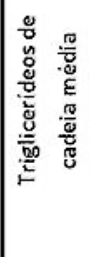 } & \multirow[b]{2}{*}{$\begin{array}{l}\text { Ácido caprilico C 8:0 } \\
\text { Ácido caprico C 10:0 }\end{array}$} & & & \\
\hline & & & & & 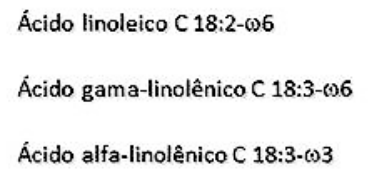 \\
\hline & 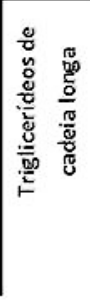 & $\begin{array}{l}\text { Ácido miristico C 14:0 } \\
\text { Ácido palmítico C 16:0 } \\
\text { Ácido esteárico C 18:0 } \\
\text { Ácido araquídico C 20:0 } \\
\text { Ácido lignocérico C 24:0 }\end{array}$ & 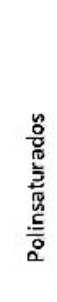 & 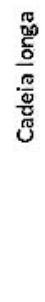 & 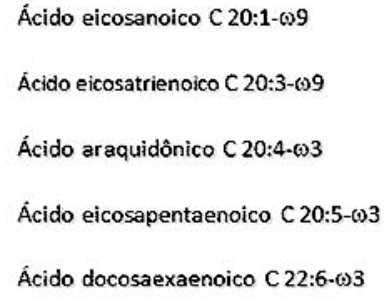 \\
\hline
\end{tabular}

Figura 2 - Classificação dos lipídeos segundo a presença de duplas ligações.

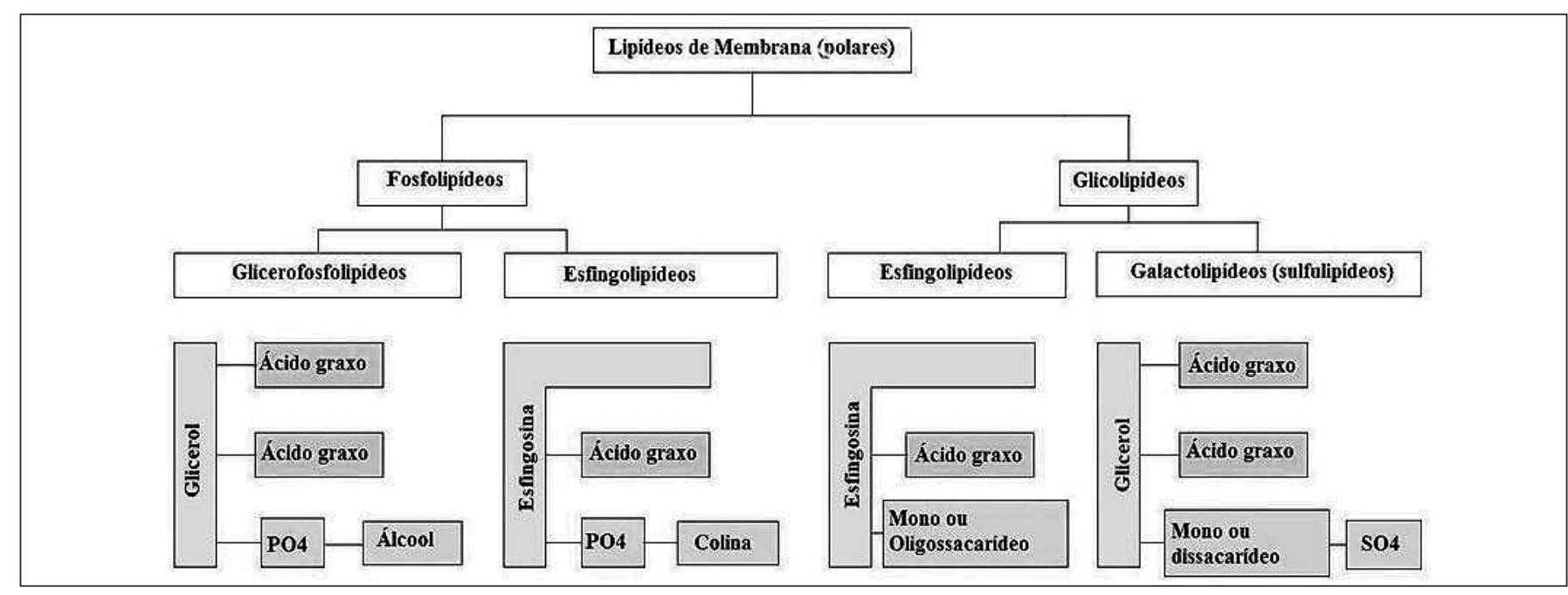

Figura 3 - Lipídeos em membranas.

Quadro 1 - Principais funções dos lipídeos².

Fornecimento energético

Palatabilidade aos alimentos

Fornecimento de ácidos graxos essenciais

Estoque de energia

Proteção mecânica a ossos e órgãos

Homeostase térmica

Transporte de vitaminas lipossolúveis

Síntese de hormônios

Síntese de estruturas celulares (membrana fosfolipídica e bainha de mielina)

Mediadores intra e extracelulares

Participação no processo inflamatório e estresse oxidativo (precursores de mediadores inflamatórios: leucotrienos, prostaglandinas, prostaciclinas, tromboxane, entre outros) 


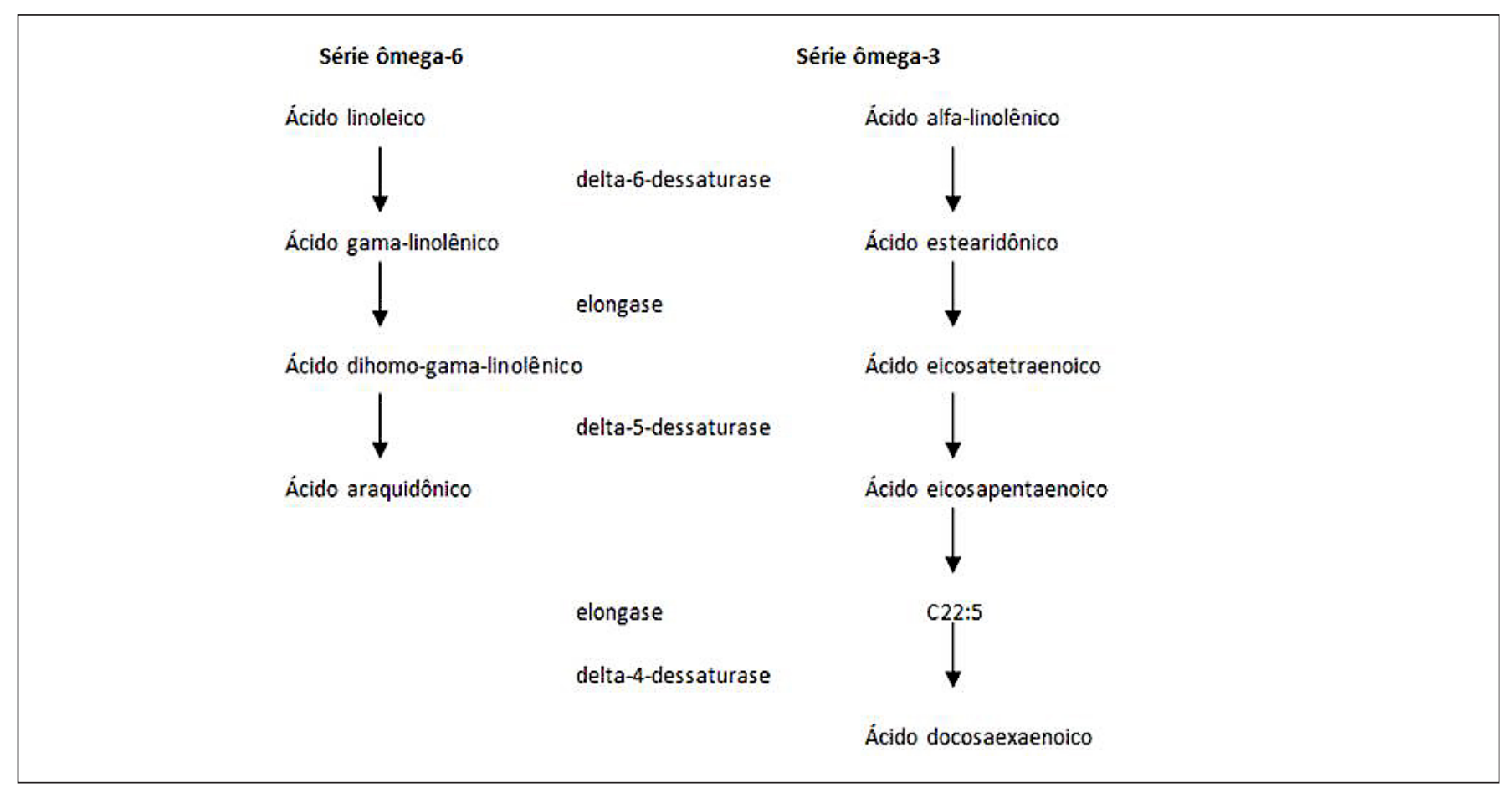

Figura 4 - Sintese dos ácidos graxos polinsaturados de cadeia longa.

Os ômegas 3 são ácidos graxos polinsaturados, com 3 duplas ligações. Eles podem ser representados por letras gregas minúsculas, que se referem à posição do carbono na molécula. Desta maneira, alfa se refere ao primeiro carbono adjacente ao grupo carboxila $(\mathrm{COOH})$, beta ao segundo carbono e ômega ao último carbono, ou ao carbono adjacente ao grupo metila terminal. A denominação ômega 3 indica que a primeira dupla ligação se encontra no carbono de número 3 , contado a partir do terminal metila $(\mathrm{CH} 3)$ e representado pelo símbolo numérico C18:3n-3, chamado de ácido alfa linolênico, sendo 18 o número de carbonos, o primeiro número 3 o número de duplas ligações, e n-3 significa que a primeira ligação dupla se encontra no terceiro carbono a partir do radical metila $(\mathrm{CH} 3)^{1}$. Os ácidos graxos ômega 3 de importância para o ser humano são o ácido alfa linolênico, o ácido eicosapentaenoico (EPA) e o DHA. EPA e DHA, assim como o ARA, recebem o nome de LCPUFAs, sigla derivada do inglês para "ácidos graxos polinsaturados de cadeia longa", uma vez que a conversão do precursor, ácido alfa-linolênico, em EPA e DHA passa por processos de elongação e dessaturação da molécula ${ }^{4,5}$.

O ácido alfa linolênico é um ácido graxo essencial, ou seja, não é sintetizado pelo organismo humano. Ele desempenha importantes funções na estrutura das membranas celulares e nos processos metabólicos. Além disso, ele é substrato para a síntese de ácidos graxos de cadeias maiores e com maior número de ligações duplas, como EPA (20:5n-3) e DHA (22:6n-3). EPA e DHA são encontrados em peixes, como salmão, cavala, arenque, etc. Apesar de o ácido alfa linolênico, no ser humano, ser convertido em EPA e DHA, não se sabe ao certo qual porcentagem é realmente convertida, mas estima-se que seja bastante baixa, da ordem de $5 \%$ para EPA e 0,5\% para DHA. Sabe-se que crianças, especialmente as mais jovens, devido à sua imaturidade enzimática, não conseguem converter todo o DHA necessário ao seu desenvolvimento a partir do ácido alfa linolênico ${ }^{4,5}$.

\section{AÇÕES BIOLÓGICAS DO DHA}

As ações biológicas dos ácidos graxos ômega 3, basicamente, são: prevenção de aterosclerose e alterações cardiovasculares, participar do desenvolvimento normal da placenta e do crescimento fetal, do desenvolvimento e metabolismo neural, da visão e da imunidade $e^{6,7}$.

Ressalta-se, então, a importância do DHA nos vários estágios da vida, desde a vida intrauterina até a adulta, influenciando, além do desenvolvimento visual e cognitivo, crescimento, saúde óssea, função imunológica e prevenindo doenças cardiovasculares ${ }^{6,7}$.

O DHA está envolvido na regulação do crescimento celular por meio da modulação gênica. A prova disto é o efeito do DHA na maturação funcional da retina, onde este ácido promove um efeito direto na diferenciação dos fotorreceptores. Vale lembrar que este efeito se inicia na vida intrauterina, mas só termina no final da primeira infância, demonstrando a importância de níveis adequados de DHA no feto, recém-nascido, lactente e pré-escolar ${ }^{8}$. 
O DHA constitui uma parte muito importante das diferentes estruturas cerebrais, entre as quais se destacam?:

a) $65 \%$ dos lipídios totais do cérebro são LCPUFAS e, desta porcentagem, mais de $85 \%$ são constituídos por DHA;

b) DHA acumula-se principalmente nos fosfolipídios cerebrais do córtex cerebral;

c) DHA é componente fundamental da mielina;

d) As maiores concentrações de DHA encontram-se no córtex cerebral e nos cones e bastonetes da retina.

O DHA também tem funções relevantes como componente funcional do sistema nervoso central, como, por exemplo ${ }^{10}$ :

a) Intervém na expressão de proteínas relacionadas ao processo de aprendizado e de plasticidade cerebral,

b) Tem função relevante no processo de geração de energia nos neurônios,

c) No córtex pré-frontal, tem relação com o desenvolvimento das funções executivas, particularmente durante os primeiros cinco anos de vida.

Também podemos apontar que a deficiência de DHA provoca uma troca de ácidos graxos na membrana celular, mais evidente nas células nervosas e retinianas, onde ocorre uma alteração na permeabilidade celular. Esta permeabilidade é ainda mais afetada quando ocorre substituição de um ácido graxo polinsaturado por saturado, colocando em risco a integridade da célula, com alteração da molécula de fosfolipídio e prejuízo na sua funçãon ${ }^{1}$.

O Quadro 2 resume as consequências da deficiência de DHA no desenvolvimento cognitivo e visual da criança ${ }^{12}$.

Em relação ao desempenho cognitivo, os estudos demonstram melhores notas em testes de quociente de desenvolvimento aos 18 meses de idade, melhores testes de quociente de inteligência aos 5 anos de idade e melhores notas em olimpíadas mundiais de matemática em idade escolar; na visão, destaca-se melhor acuidade visual aos 12 meses de idade e, na imunidade, menor incidência de afecções respiratória (infecções de vias aéreas superiores e sibilância) e também menor frequência de manifestações alérgicas, como asma e dermatite atópica ${ }^{8,13-15}$.

Inúmeros efeitos de EPA e DHA em respostas funcionais de células envolvidas na inflamação e imunidade se estabeleceram ao longo dos últimos 40 anos.

Estes efeitos incluem inibição da quimiotaxia leucocitária, expressão da molécula de adesão e interações adesivas entre leucócitos e endotélio, produção de eicosanoides, como prostaglandinas e leucotrienos, produção de citocinas pró e antinflamatórias, como fator de necrose tumoral (TNF) e interleucinas (IL), especialmente a IL-6, reatividade das células T e reforço na fagocitose (Quadro 3) ${ }^{16}$.

Quadro 2 - Deficiência de DHA e prejuízo do desenvolvimento cognitivo e visual em crianças ${ }^{12}$.

\begin{tabular}{ll}
\hline Prejuízo do desenvolvimento cognitivo & Menor número de células nervosas \\
& Menos DHA nas células nervosas \\
& Menor produção de neurotransmissores (acetilcolina, dopamina e norepinefrina) \\
& Menor deposição de mielina \\
& Menor número de sinapses
\end{tabular}

Prejuízo do desenvolvimento visual

Inadequada maturação funcional da retina

Menor diferenciação dos fotorreceptores

Quadro 3 - Efeitos de EPA e DHA nas células imunes e inflamatórias ${ }^{16}$.

\begin{tabular}{ll}
\hline Tipo de célula & \\
\hline Células endoteliais & $\downarrow$ expressão da adesão molecular \\
& $\downarrow$ adesão de leucócitos \\
& $\downarrow$ produção de citocinas inflamatórias \\
Neutrófilos & $\downarrow$ quimiotaxia \\
& $\downarrow$ adesão às células endoteliais \\
& $\downarrow$ produção de eicosanoides derivados do ácido araquidônico \\
Monócitos e macrófagos & $\downarrow$ quimiotaxia \\
& $\downarrow$ expressão da adesão molecular \\
& $\downarrow$ adesão às células endoteliais \\
& $\downarrow$ fagocitose \\
& $\downarrow$ produção de eicosanoides derivados do ácido araquidônico \\
& $\downarrow$ produção de citocinas inflamatórias \\
Células apresentadoras de antígenos & $\downarrow$ apresentação de antígenos \\
& $\downarrow$ adesão da expressão molecular \\
Células T & $\downarrow$ adesão às células endoteliais \\
& $\downarrow$ produção de citocinas T-helper 1 \\
\hline
\end{tabular}


Todos estes efeitos, interpretados no contexto da redução da inflamação, beneficiam condições antinflamatórias. Modificações nas membranas celulares e disponibilidade de substratos para a síntese de eicosanoides são mecanismos bem conhecidos e bastante importantes para explicar as ações antinflamatórias e imunomoduladoras do EPA e do DHA. Mais recentemente, efeitos sobre vias de transdução de sinal e perfis de expressão de gene foram identificados para também desempenhar o mesmo papel.

Ao longo dos últimos 10 anos, avanços significativos na compreensão dos mecanismos de ação do EPA e DHA foram estabelecidos. Estes mecanismos incluem identificação de novas ações de mediadores lipídicos, novas interações entre esses mediadores e a descrição de uma família inteiramente nova de mediadores lipídicos, resolvinas, protectinas e maresinas, que possuem ação antinflamatória e, mais importante, são essenciais para a resolução da inflamação ${ }^{16}$.

Esses mediadores, resolvinas, protectinas e maresinas, podem explicar muitas das ações imunológicas do EPA e do DHA, como a inibição da ativação do fator de transcrição inflamatório NF-kB dentro de células imunes, como os macrófagos. Estudos recentes sugerem três mecanismos pelo qual os ácidos graxos ômega 3 podem ter este efeito: ativação do receptor proliferador ativado de peroxissoma (PPAR), que interage com NF-kB, impedindo sua translocação nuclear; interferência nos primeiros eventos de membrana envolvidos na ativação de NF-kB; ação por meio de receptor acoplado da proteína $G(G P R)$, que inicia uma cascata de sinalização antinflamatória, que inibe a sinalização e leva à inibição da ativação do NF-kB (Figura 5) ${ }^{16}$.
Dentre as células-T, bem como em células com relevância para respostas imunes e inflamatórias, EPA e DHA podem precocemente atuar em eventos que envolvem a formação de estruturas denominadas pontes lipídicas, que reúnem várias proteínas para formar uma plataforma eficaz de sinalização intracelular. A descoberta das ações de EPA e DHA em pontes lipídicas e sobre outros complexos de sinalização em membranas celulares, por meio do receptor acoplado de proteína (GPR120), mostra a membrana citoplasmática como ponto chave de ação destes ácidos graxos ${ }^{16}$.

Apesar dos progressos alcançados no tratamento da asma, a prevalência desta doença continua aumentando. Apesar do tratamento farmacológico da asma ser eficaz, muitas vezes, apresenta efeitos colaterais significativos. Terapias alternativas para reduzir intervenções farmacológicas seriam benéficas e já existem evidências de que a modificação dietética teria potencial para reduzir a prevalência e a gravidade da asma ${ }^{17}$.

Um possível fator para se explicar o aumento da incidência de asma nas sociedades ocidentais poderia ser o consumo de dietas pró-inflamatórias. Na dieta ocidental típica, ingere-se 20 a 25 vezes mais ácidos graxos ômegas 6 do que ômega 3, provocando a liberação de metabólitos pró-inflamatórios do ácido araquidônico (leucotrienos e prostaglandinas) ${ }^{17}$.

Assim, a suplementação de EPA e DHA como um potencial modificador da hiperreatividade brônquica traria benefícios no controle da asma. Existem muitos estudos

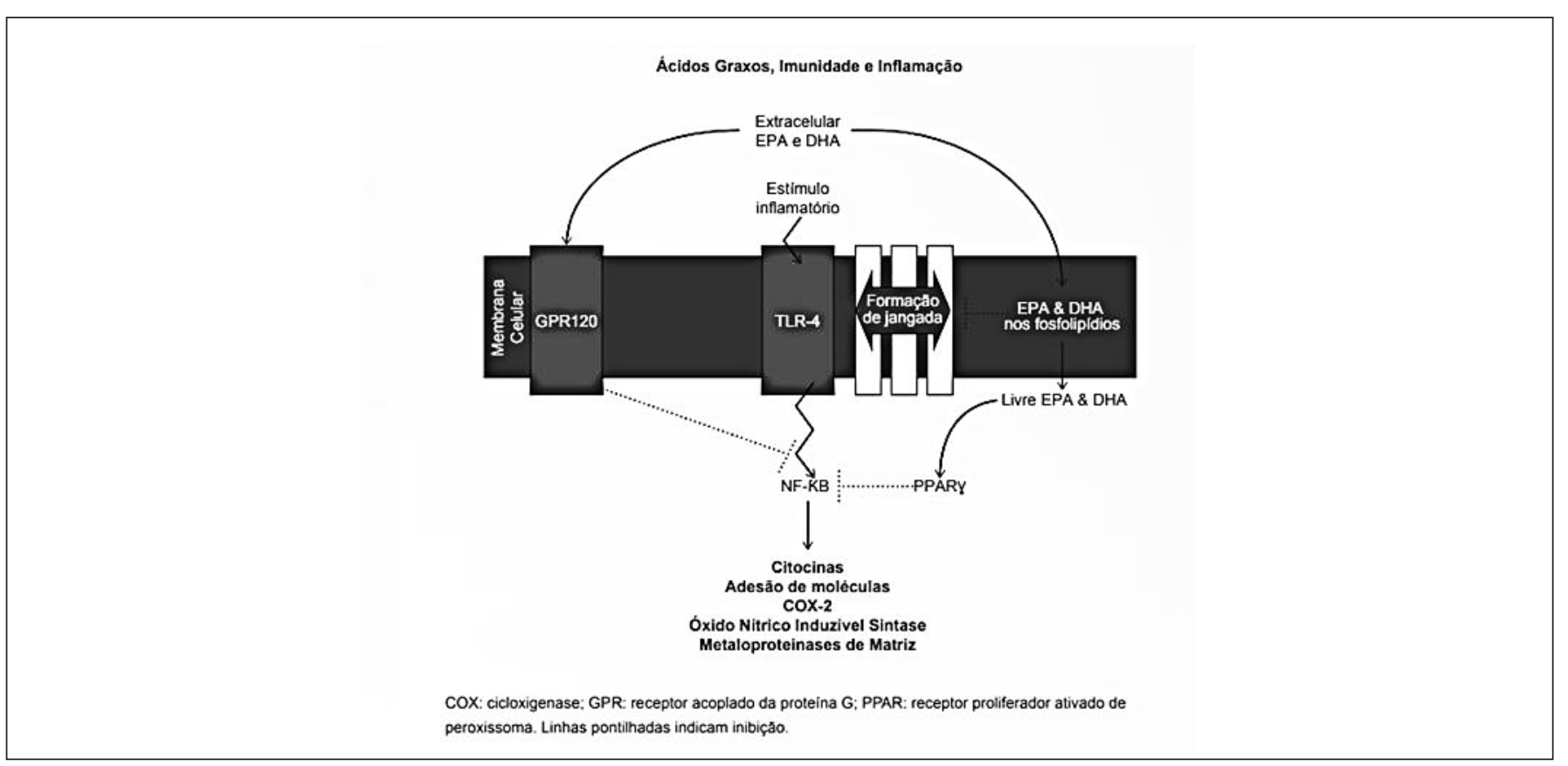

Figura 5 - Diferentes mecanismos de inibição do fator de transcrição NF-kB pelo EPA e DHA ${ }^{16}$. 
epidemiológicos e observacionais que investigaram o efeito da ingestão de peixe ou suplementação de ácido graxo ômega 3 durante gravidez, lactação, infância e vida adulta em indivíduos alérgicos. Os resultados indicam efeitos protetores e sugerem uma relação causal entre a diminuição da ingestão de ômega 3 e um número crescente de indivíduos com asma ou outras doenças alérgicas ${ }^{18}$.

A explicação desta relação foi possível graças à descoberta de mediadores específicos (protectinas, resolvinas e maresinas) que são gerados a partir de EPA e DHA, por meio de várias reações enzimáticas. Estes mediadores regulam a inflamação eosinofílica das vias aéreas e outros sítios e promovem a resolução de inflamação. Vários relatos demonstram que a biossíntese desses mediadores está prejudicada, principalmente na asma grave ${ }^{18}$.

A Figura 6 mostra mediadores pré e antinflamatórios derivados de ácidos graxos ômega 6 e ômega 3. Ácido araquidônico é precursor de eicosanoides (prostaglandinas e leucotrienos) que têm funções pró-inflamatórias, induzindo o aparecimento de fenômenos alérgicos. Em contraste, EPA e DHA são convertidos em metabólitos bioativos, tais como resolvinas, protectinas e maresinas, que apresentam propriedades antinflamatórias e pró-resolução de processo alérgico ${ }^{18}$.
A dieta tem papel crucial na modulação da composição da microbiota intestinal. Apesar do grande número de publicações sobre os efeitos dos carboidratos nessa microbiota, são poucos os estudos com proteínas e lipídeos, principalmente com DHA e na faixa etária pediátrica.

Vários fatores influenciam a composição da microbiota intestinal, incluindo fenótipo, idade, sexo, índice de massa corporal, estilo de vida, função imune, ambiente, uso de antibióticos, drogas de adição, probióticos e dieta. Em situações onde há uma ruptura entre esses fatores, ocorre a disbiose intestinal, um desequilíbrio da microbiota intestinal, que poderá levar ao aparecimento de várias doenças locais e sistêmicas ${ }^{19}$.

As evidências entre disbiose e estado patológico estão crescendo, em particular em alguns distúrbios metabólicos e inflamatórios. Diferentes bactérias intestinais modulam funções imunes que podem desempenhar papéis pró e antinflamatório e, assim, a composição da microbiota intestinal pode determinar, em parte, o nível de resistência à infecção e susceptibilidade a doenças inflamatórias e o DHA parecem exercer importantes efeitos sobre o ambiente intestinal (Figura 7) ${ }^{19}$.

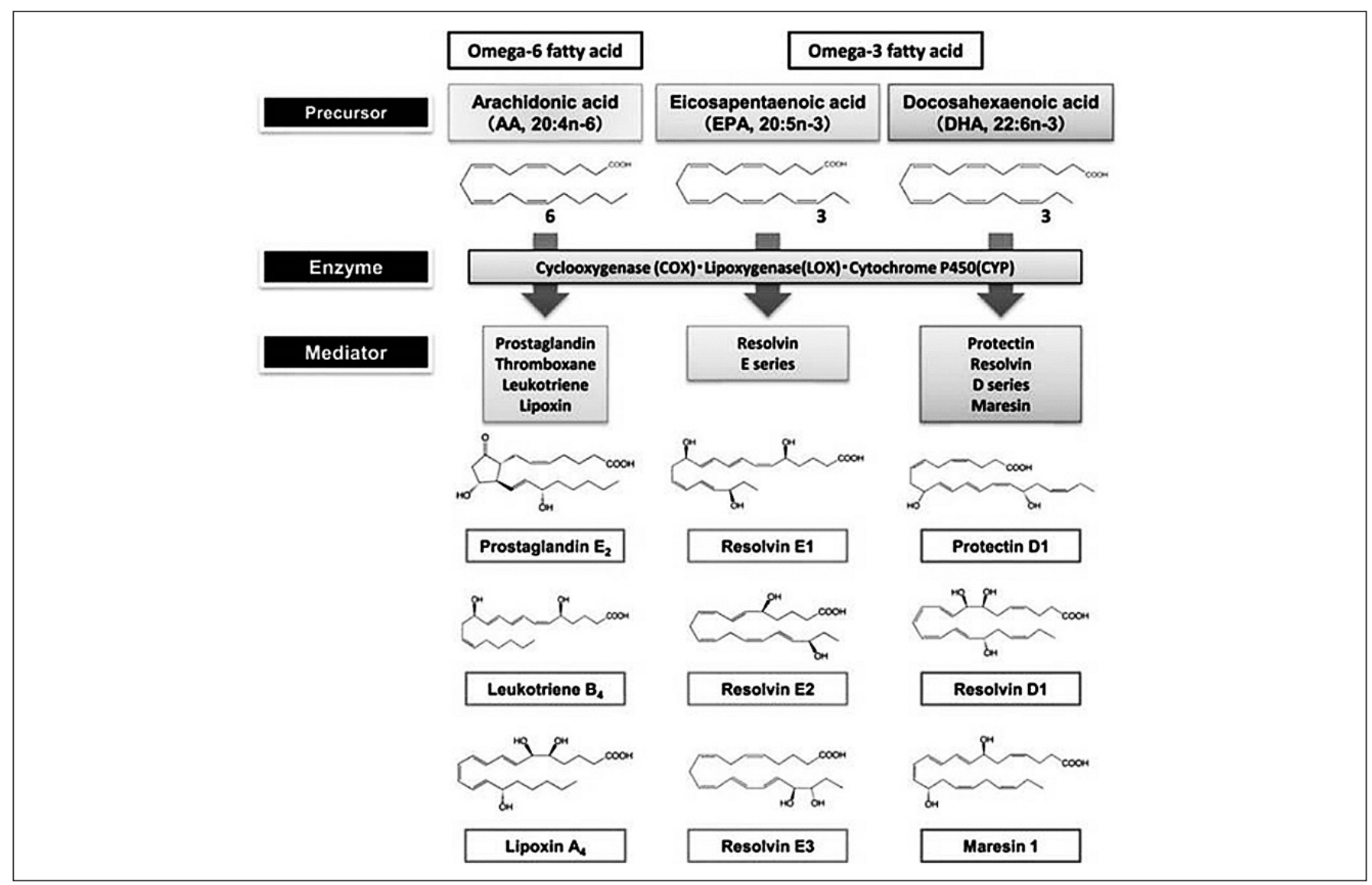

Figura 6 - Mediadores pró e antinflamatórios derivados de ácidos graxos ômega 6 e ômega $3^{18}$. 


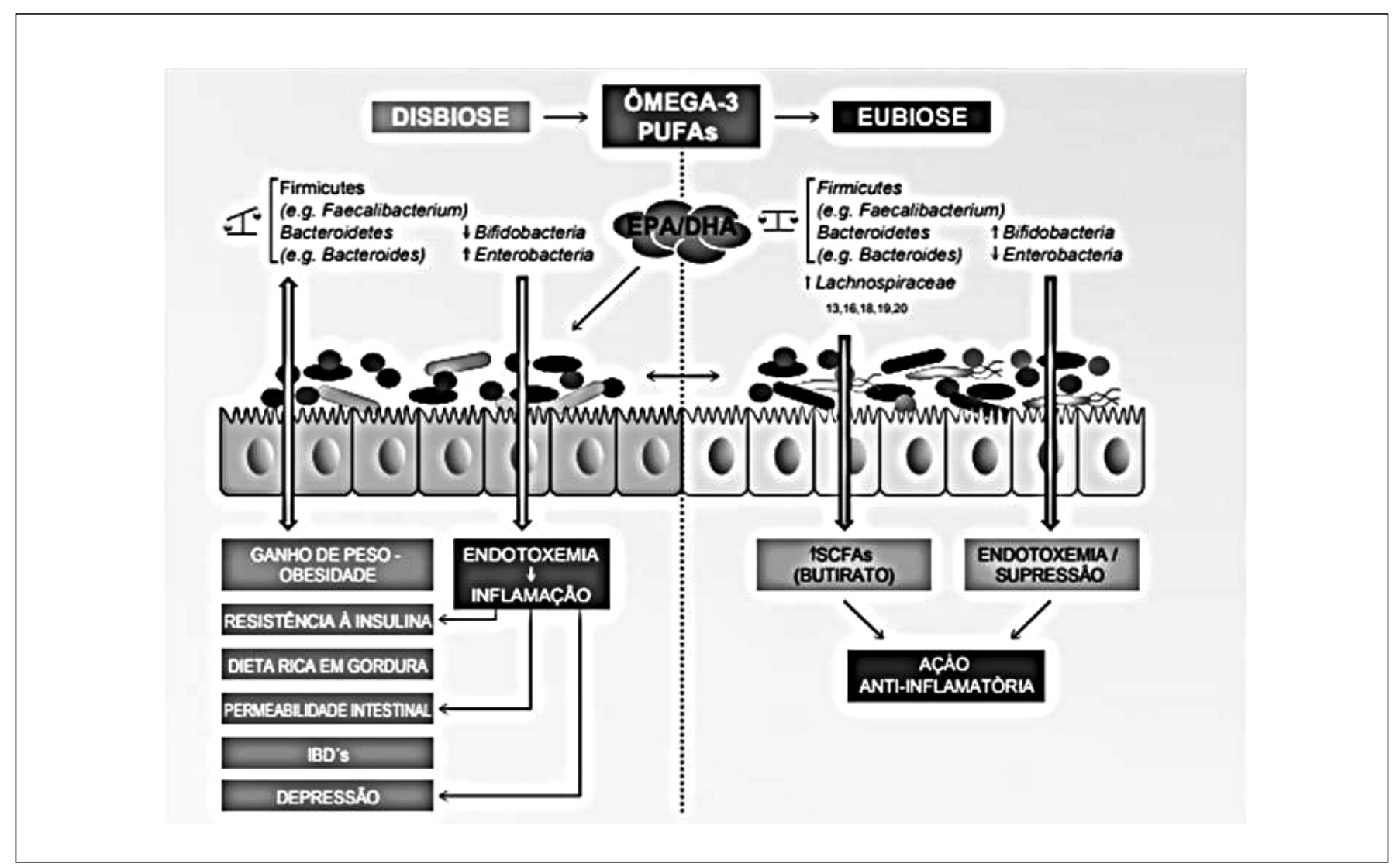

Figura 7 - Ação do DHA na restauração da eubiose na microbiota intestinal ${ }^{19}$.

\section{DESENVOLVIMENTO DAS FÓRMULAS INFANTIS}

A alimentação de lactentes desmamados tem sido uma grande preocupação há muito tempo. Já foram utilizados amas de leite, leite de vaca integral ou de outros animais, como mula, cabra, etc.

As primeiras "fórmulas infantis" fabricadas nada mais eram do que leite de vaca integral evaporado, acrescidas de xarope de milho e/ou lactose. $O$ conteúdo proteico dessas "fórmulas" era extremamente alto e a fração lipídica compreendia a própria gordura do leite de vaca, ou seja, ácidos graxos saturados, que são pouco absorvidos pelos lactentes e contém mínimas quantidades de ácidos graxos essenciais ${ }^{20}$.

A composição das fórmulas infantis evoluiu consideravelmente; cada um dos macronutrientes (proteínas, lipídeos e carboidratos) foi modificado nas fórmulas infantis atualmente disponíveis, a fim de se aproximar da composição do leite humano.

Embora a composição do leite humano forneça uma base para a composição das fórmulas infantis, estas não reproduzem a composição do leite materno por diversas razões. Primeiro, o leite humano contém componentes como hormônios, fatores de crescimento, anticorpos, enzimas e células vivas que são praticamente impossíveis de serem adicionados às fórmulas. Segundo, as fórmulas infantis são feitas, em sua maioria, de leite de vaca, que frequentemente fornece nutrientes que são diferentes na forma química e composição em relação ao leite humano, inclusive com menor biodisponibilidade.

\section{LIPÍDEOS NAS FÓRMULAS INFANTIS}

Os lipídeos fornecem $40 \%$ a $50 \%$ da energia do leite humano e das fórmulas infantis. Atualmente, essa energia é fornecida por uma mistura de óleos vegetais, que são mais bem absorvidos e fornecem quantidades mais apropriadas de ácidos graxos essenciais. Essas misturas são elaboradas para fornecer um equilíbrio de ácidos graxos saturados, monoinsaturados e polinsaturados ${ }^{20}$.

Os óleos comumente utilizados incluem coco (fonte de ácidos graxos de cadeia média), oleína de palma (fonte de ácidos graxos saturados de cadeia longa, principalmente ácido palmítico) e óleos de soja, milho e girassol (fonte de ácidos graxos polinsaturados ${ }^{20}$. Em contraste com o leite humano, que tem altas concentrações de colesterol, as fórmulas infantis contêm pouco ou não contém colesterol ${ }^{20}$.

É importante salientar a adição de ácidos graxos essenciais (ácidos linoleico e linolênico) nas fórmulas infantis, nas quantidades e proporções do leite humano, ou seja, 5 a 15:1 (ácido linoleico:ácido linolênico) ${ }^{21}$. Também é 
importante ressaltar a adição de LCPUFAs, ARA e DHA, nas quantidades e proporções do leite humano, ou seja, 0,2\% a $0,5 \%$ do total de lipídeos de DHA e até $1 \%$ de ARA, com uma relação ARA:DHA de $2: 1^{4,21}$.

\section{DHA INCORPORADO AO FOSFOLIPÍDEO}

Atualmente, as fórmulas infantis de rotina possuem 100\% dos LCPUFAs (DHA e ARA) ligados ao triglicerídeo, condição benéfica e importante para o desenvolvimento visual, cerebral imunológico do lactente ${ }^{22}$. Contudo, estudos recentes têm demonstrado que a adição de LCPUFAs ligados aos fosfolipídeos (PL) em fórmulas infantis, entre $12 \%$ e $20 \%$, possibilita o aumento de cerca de duas vezes a incorporação do DHA no cérebro e outros tecidos ${ }^{22,23}$. Portanto, a estrutura lipídica dos LCPUFAs presente nas fórmulas infantis determina sua biodisponibilidade.

Diversos estudos apontam que o tipo de lipídio incorporado nas membranas celulares pode influenciar a programação metabólica, uma vez que a maior incorporação dos LCPUFAs nas membranas celulares contribui para ${ }^{22-24}$ :

- Melhor formação e funcionamento de órgãos e tecidos;

- Desenvolvimento físico, imunológico, cerebral e metabólico;

- Redução do risco de doenças crônicas não transmissíveis.

Este fato reflete a influência dos LCPUFAs (DHA e ARA) no imprinting metabólico. O termo "imprinting" metabólico descreve um fenômeno pelo qual uma experiência nutricional precoce, atuando durante um período crítico e específico do desenvolvimento, pode acarretar um efeito duradouro e persistente ao longo da vida do indivíduo, predispondo-o ou não a determinadas doenças. Existe um papel dos ômegas na proliferação e diferenciação de pré-adipócitos em adipócitos; o ômega 3 parece reduzir a proliferação de adipócitos, enquanto o ômega 6 parece estimular essa proliferação ${ }^{25}$.

Nesse sentido, a adequada ingestão desses LCPUFAs, assim como a suplementação de DHA, na gestação e lactação, parece estar envolvida com o melhor desenvolvimento do metabolismo e sistemas cerebral e imune do lactente. Portanto, ao se incluir os LCPUFAs ligados aos fosfolipídios (PL) como fonte de DHA e ARA, a composição de fórmulas infantis se aproxima da composição do leite materno.

Willatts et al. ${ }^{26}$ estudaram o efeito de fórmula sem e com LCPUFAs ligados aos PL no desenvolvimento cognitivo de 44 lactentes de termo. Os lactentes foram randomizados para receber fórmula com PL ( $n=21)$ ou sem PL $(n=23)$, durante os primeiros quatro meses de vida. $O$ teste de desenvolvimento cognitivo foi aplicado aos 10 meses de idade. Notaram-se diferenças no desenvolvimento cognitivo dos lactentes que utilizaram as fórmulas com LCPUFAs ligados aos $\mathrm{PL}$, em relação aos que não receberam (Tabela 1).

Esta coorte foi analisada aos 6 anos de idade e as crianças foram submetidas a testes de processamento temporal auditivo,
Tabela 1 - Escores na resolução de problemas (fórmulas com PL x fórmula padrão) ${ }^{26}$.

\begin{tabular}{lccc}
\hline Escore & $\begin{array}{c}\text { Fórmula com } \\
\text { PL }\end{array}$ & $\begin{array}{c}\text { Fórmula } \\
\text { padrão }\end{array}$ & $\mathbf{p}$ \\
\hline $\begin{array}{l}\text { Pontuação de intenção de } \\
\text { resolução de problemas }\end{array}$ & $14(11,8-17,1)$ & $11,5(10,0-13,3)$ & 0,035 \\
$\begin{array}{l}\text { Soluções intencionais de } \\
\text { problemas }\end{array}$ & $2(0,5-3,0$ & $0(0,0-2,0$ & 0,021 \\
\hline
\end{tabular}

teste de memória, atenção auditiva e visual e testes de inteligência. Pontuações de erro para os testes de correspondência de figuras familiares (velocidade de teste de processamento) foram os mesmos nos grupos de fórmulas, mas o grupo que recebeu fórmula com LCPUFAs ligados aos PL apresentou tempos de resposta significativamente mais rápidos. Não houve diferenças entre os grupos de fórmulas sobre as medidas de controle da atenção e inteligência. Com base nesses resultados, observa-se que a variação na oferta alimentar de LCPUFAs, assim como sua biodisponibilidade nos primeiros meses de vida, pode ter consequências em longo prazo para o desenvolvimento da função cognitiva futura na infância ${ }^{27}$.

A ingestão de ácidos graxos polinsaturados de cadeia longa pode fornecer nutrientes específicos para a construção das membranas celulares, formação das sinapses e produção de neurotransmissores. $O$ principal componente na comunicação neuronal, a sinapse, consiste de $\mathrm{FL}$ que são ricos em DHA e ARA. Várias evidências sugerem que o ômega 3 pode afetar a disponibilidade de nutrientes no cérebro, pela alteração dos componentes vasculares, oferta de sangue no cérebro, integridade da barreira cerebral e eficiência do transporte e incorporação de nutrientes no cérebro ${ }^{28}$.

Um ensaio clínico conduzido por Bouwstra et al. ${ }^{29}$, composto por três grupos: lactentes que receberam fórmula sem adição de PL $(n=131)$; com adição de LCPUFAs ligados aos $\mathrm{PL}$ e que foram amamentados ( $\mathrm{n}=147$ ), por um período de 2 meses, com o objetivo de observar melhora na qualidade dos movimentos generalizados em lactentes saudáveis, revelou diferenças favoráveis ao desenvolvimento motor dos lactentes utilizando as fórmulas PL e amamentados em relação aos não suplementados (Figura 8 ).

Estudo realizado por Liu et al. ${ }^{23}$ com leitões recémnascidos demonstrou superior eficácia na incorporação de DHA em fórmula enriquecida com este LCPUFA proveniente dos PL em relação aos triglicerídeos. Tal resultado pode ser explicado pelo fato de que, aproximadamente, $10 \%$ do peso do cérebro e $50 \%$ do peso seco são formados por lipídeos, sendo metade fosfolipídeos. Os fosfolipídeos do tecido cerebral contêm grandes proporções de DHA e ARA. Altas concentrações de DHA em retina e de DHA e ARA em cérebro demonstram que estes ácidos graxos têm importante função no desenvolvimento cerebral e visual da criança (Figura 9). 


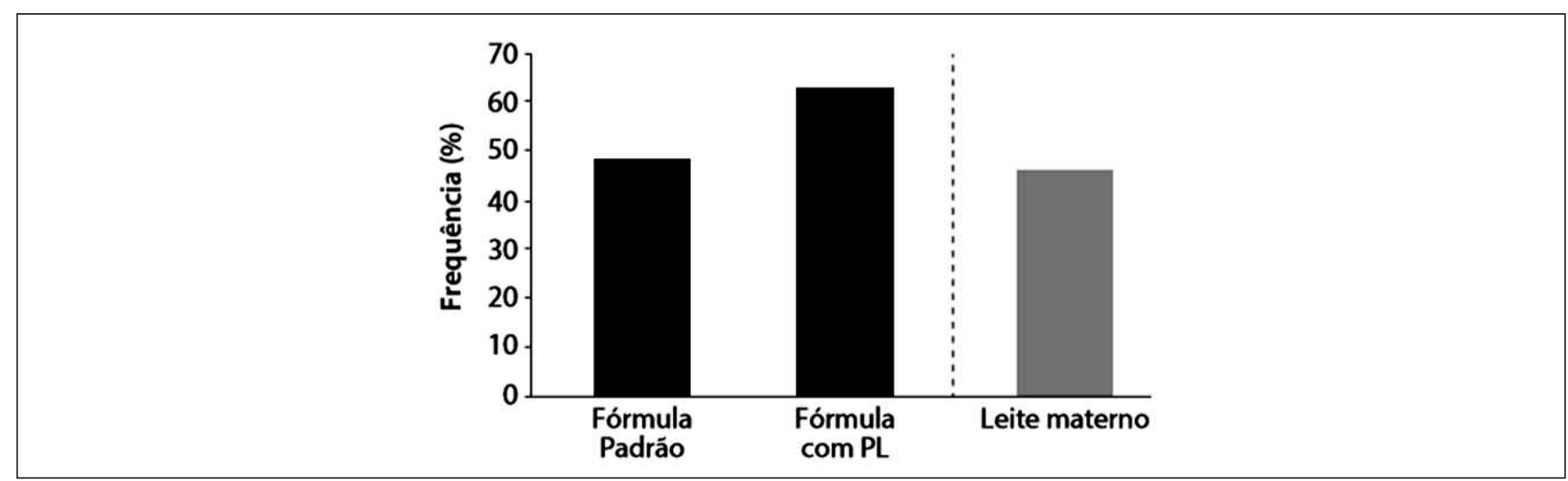

Figura 8 - Padrão de qualidade de movimentos aos 3 meses de idade ${ }^{29}$.

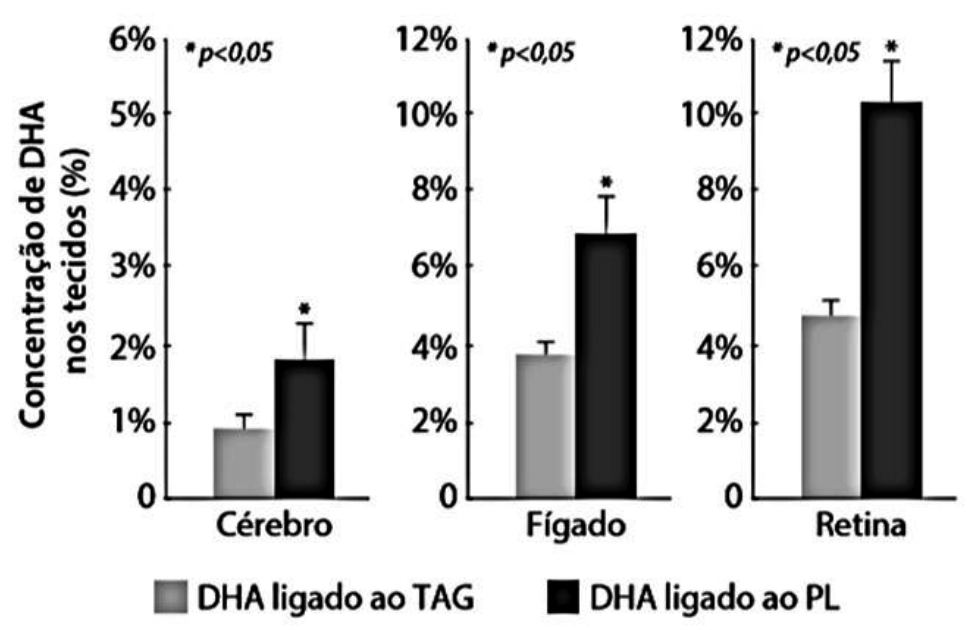

Figura 9 - Diferenças na incorporação de DHA ligado aos fosfolipídeos em vários tecidos.

Com base nestas evidências, pode-se propor que as células captam o nutriente e ativam uma cascata de reações, entre elas, a ativação de fatores de transcrição. Estes enviam as informações para os genes, os quais as transmitem para o exterior do gene por meio dos RNA mensageiros que produzem as proteínas, exteriorizando a resposta ao estímulo (nutriente). Portanto, o nutriente pode alterar qualquer uma destas etapas, e a resposta celular depende do nutriente captado, condição entendida como nutrigenômica ${ }^{30}$.

Desse modo, ante as evidências, é possível concluir que o uso do PL ligado ao DHA e ARA é seguro e apresenta boa tolerabilidade e resposta clínica favorável, pela maior incorporação de LCPUFAs nas membranas celulares.

É importante salientar que não existem relatos na literatura de toxicidade em decorrência da ingestão alimentar de LCPUFAs ligados aos PL. Os estudos não encontraram diferenças em ganho de peso, comprimento e perímetro cefálico; também não foram relatados efeitos adversos, como alergias ou intolerâncias.

\section{ÁCIDO PALMÍTICO}

O leite humano contém 3\% a $4 \%$ de lipídeos, sendo $98 \%$ na forma de triglicerídeos, $1 \%$ de fosfolipídeos, 0,5\% de esteróis, além de ácidos graxos livres, mono e diacilgliceróis. A maioria dos lipídeos está sob a forma de glóbulos com $4 \mu \mathrm{m}$ de diâmetro, envoltos por uma membrana contendo fosfolipídeos e proteínas.

Os ácidos graxos são, em sua maioria, de cadeia longa, com cerca de $50 \%$ sob a forma saturada e $50 \%$ insaturada ${ }^{31,32}$.

Mais de 200 ácidos graxos já foram identificados no leite humano, mas apenas 7 correspondem a $90 \%$ do total de lipídeos, sendo os principais: oleico, palmítico, esteárico, mirístico, láurico, linoleico e linolênico (Figura 10) ${ }^{31,33 .}$

Dentre os ácidos graxos saturados de cadeia longa, o ácido palmítico representa $20 \%$ a $25 \%$ do total de lipídeos e merece especial atenção ${ }^{32}$.

A maior parte de ácido palmítico do leite humano encontra-se na posição 2 (B-2) do triacilglicerol (Figura 11). Essa configuração única é a principal causa da eficiência da absorção de gordura do leite humano ${ }^{31}$. 


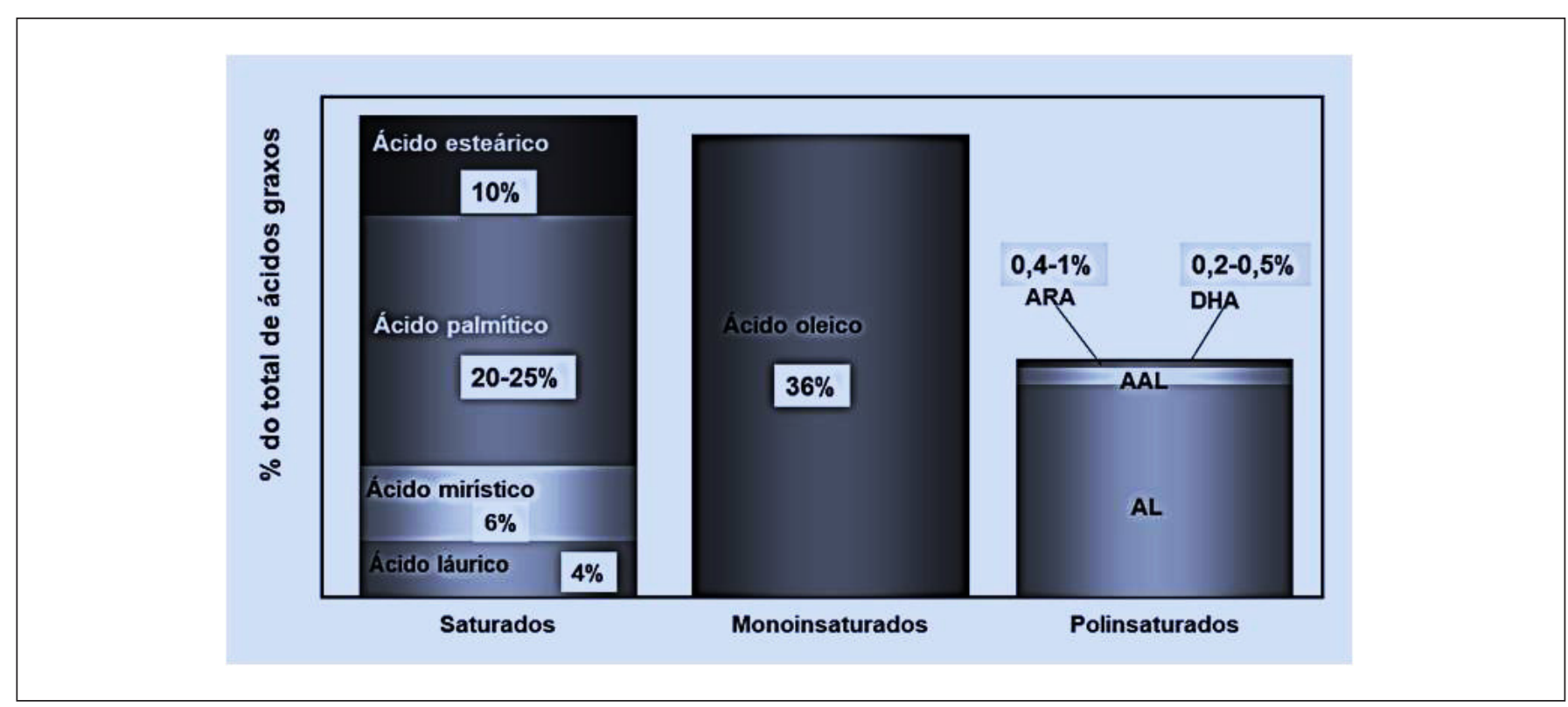

Figura 10 - Perfil lipídico do leite humano ${ }^{33}$. AAL: ácido alfa linolênico; $A L$ : ácido linoleico.

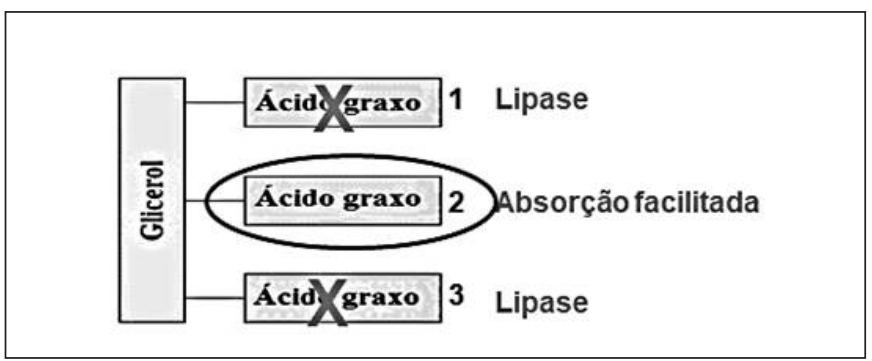

Figura 11 - Configuração do ácido palmítico na posição $\beta$-2 no leite humano.

Dos três ácidos graxos ligados ao glicerol, o ácido palmítico se encontra na posição 2 (B-2), central, e as posições 1 $(B-1)$ e 3 (B-3) são ocupadas por ácidos graxos insaturados (oleico e/ou linoleico, por exemplo). A lipase hidrolisa os triglicerídeos $\beta-1$ e $\beta-3$ e o ácido palmítico na posição ß-2 mantém-se primariamente com 2-monoglicerídeo, cuja absorção é facilitada pela maior polaridade e hidrossolubilidade em conjunto com sais biliares s $^{31,32}$.

Nas situações onde o ácido palmítico encontra-se nas posições B-1 e ß-3 (ácido palmítico de origem vegetal) não ocorre hidrólise pela lipase, formando um complexo insolúvel com o cálcio, pelo processo de saponificação, provocando perda intestinal de cálcio e ácido palmítico, além do endurecimento das fezes ${ }^{33,34}$.

A maioria das fórmulas infantis comercializadas no Brasil tem, em sua mistura de óleos vegetais, a oleína de palma ou o óleo de palma, que é uma fonte natural de ácido palmítico ${ }^{35}$. Entretanto, nesses óleos (oleína e óleo de palma), o ácido palmítico encontra-se na posição B-1 e B-3 na molécula do triglicerídeo. Esta conformação, como descrito acima, prejudica sua absorção, causando prejuízos ao lactente ${ }^{35}$.
Com o avanço da ciência junto à tecnologia de alimentos, foi possível adicionar ácido palmítico na posição ß-2, via reestruturação ou modificação da molécula de lipídeos, para alterar a composição de ácidos graxos e/ou sua distribuição no glicerol. Trata-se de um avanço promissor no sentido de acrescentar nutrientes às fórmulas infantis, de forma a proporcionar benefícios clínicos mais próximos ao leite materno ${ }^{36}$.

Dentre os benefícios da adição de ácido palmítico na posição ß-2 destacam-se:

\section{Melhora na digestão e absorção de ácido graxo e de cálcio}

A ingestão de ácido palmítico na posição $B-2$ por lactentes em uso de fórmulas infantis proporcionou maior eficiência de absorção de ácido graxo e de cálcio, além de fezes mais macias, efeito que foi associado à diminuição na formação de sabões de cálcio ${ }^{37}$. Comparando-se a evolução clínico e nutricional de lactentes saudáveis em uso de leite materno, com fórmula padrão (sem ácido palmítico B-2) ou fórmulas infantis contendo ácido palmítico na posição ß-2 com e sem prebióticos, observou-se redução na excreção fecal de sabões de cálcio (Figura 12) e menor incidência de fezes endurecidas (Figura 13) nos grupos em aleitamento materno e com fórmula infantil com ácido palmítico na posição $ß-2^{37}$.

\section{Mineralização óssea}

A adição de ácido palmítico na posição ß-2 em fórmulas infantis, além de tornar sua composição semelhante ao leite materno, contribui para menor formação de sabões de cálcio, melhora absorção de nutrientes, principalmente, do cálcio, fator este que pode ser relacionado à saúde óssea, por favorecer a mineralização óssea ${ }^{38}$. 


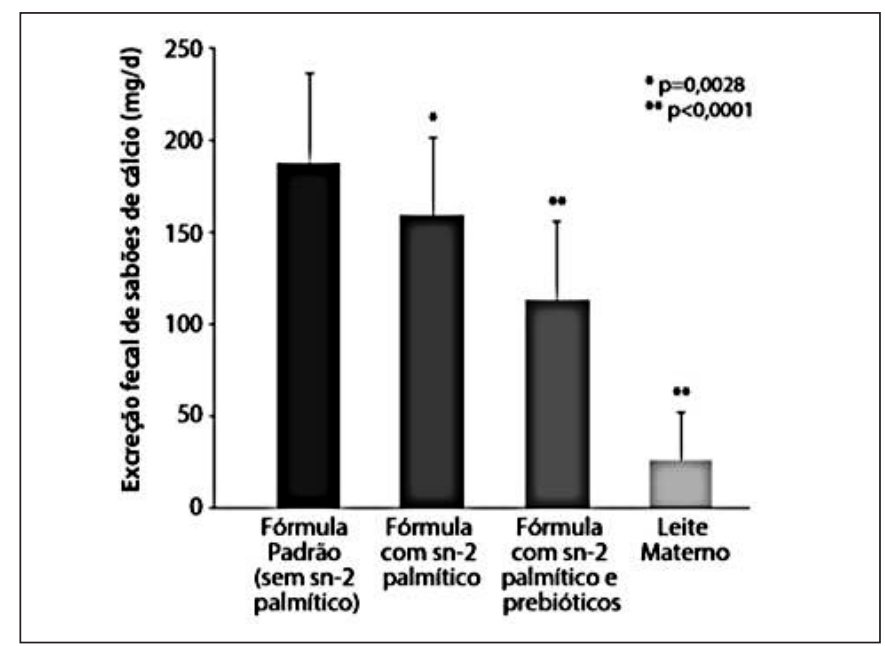

Figura 12 - Formação de sabões de cálcio ${ }^{37}$.

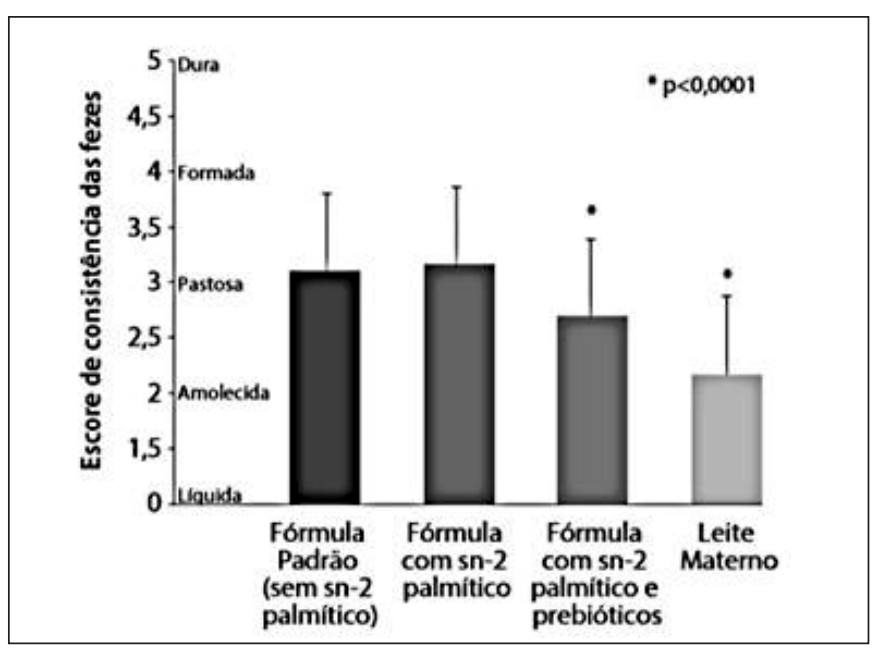

Figura 13 - Consistência das fezes ${ }^{37}$.

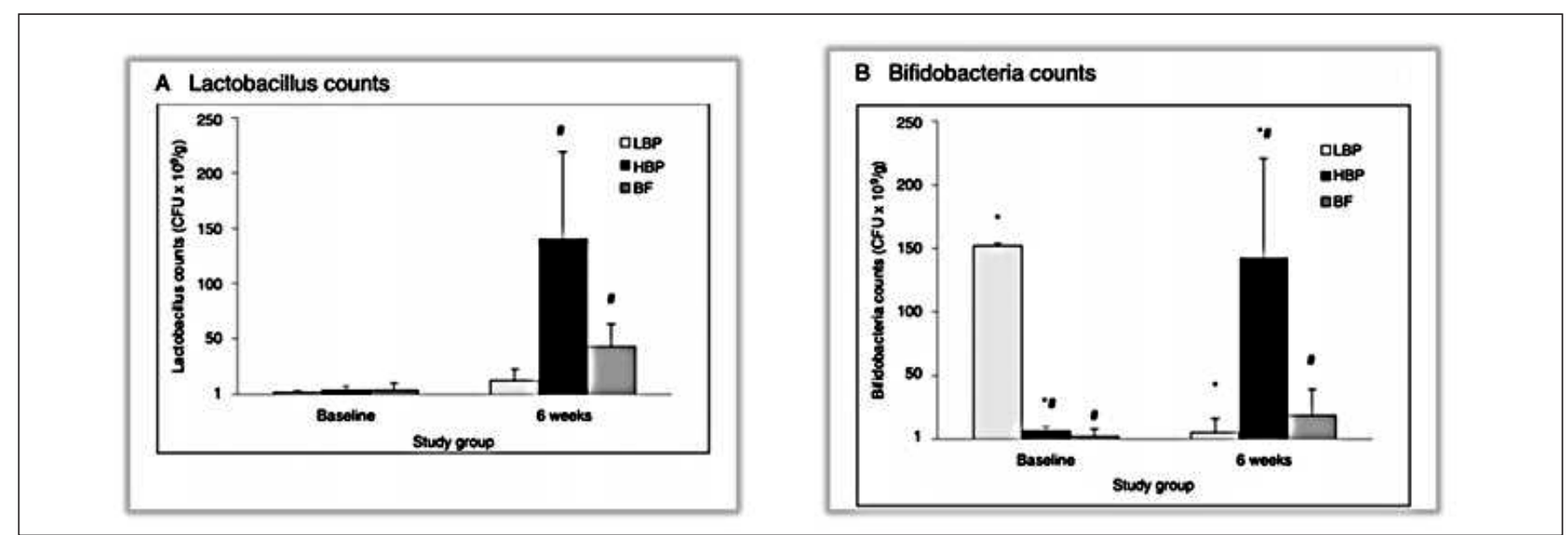

Figura 14 - Efeitos do ácido palmítico $\beta$-2 sobre a microbiota intestinal ${ }^{38}$.

\section{Microbiota intestinal}

Comparando-se o efeito de duas fórmulas infantis, diferindo na posição do ácido palmítico no triglicerídeo, obtiveram-se efeitos diferentes sobre a microbiota intestinal de lactentes. Estes achados sugerem que o B-palmitato pode afetar a composição da microbiota intestinal durante as primeiras semanas de vida, pelo maior número de colônias de Lactobacillus e bifidobactérias em fezes e, assim, proporcionar efeitos benéficos para a saúde e bem-estar dos lactentes. Esses achados enfatizam a importância da estrutura dos lipídeos em fórmulas infantis e sugerem efeitos da

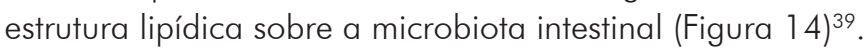

\section{CONSIDERAÇÕES FINAIS}

- Apesar da estrutura lipídica do leite materno ser extremamente complexa, ela deve servir de modelo para a dinâmica da composição lipídica das fórmulas infantis;

- A adição de LCPUFAs (ARA e DHA) ligados a fosfolipídeos em fórmulas infantis pode contribuir para um melhor desenvolvimento de lactentes, assim como atuar no sistema imunológico e no "imprinting" metabólico, reduzindo o risco de doenças crônicas não transmissíveis;

- Lactentes recebendo fórmulas com ácido palmítico B-2 apresentam maior contagem de lactobacilos nas fezes, quando comparados aos que recebem fórmulas com ácido palmítico $\beta-1$ e $\beta-3$, promovendo a manutenção da eubiose intestinal;

- Lactentes recebendo fórmulas com ácido palmítico B-2 apresentam saúde óssea similar aos lactentes em aleitamento materno, pois não ocorre perda fecal de cálcio.

\section{REFERÊNCIAS}

1. American Academy of Pediatrics. Infant nutrition and development of gastrointestinal function. In: Kleinman RE, American Academy of Pediatrics, Committee on Nutrition, eds. Pediatric nutrition handbook. $6^{\text {th }}$ ed. Elk Grove Village: American Academy of Pediatrics; 2009. p.3-28.

2. Keim SA, Daniels JL, Siega-Riz AM, Herring AH, Dole N, Scheidt PC. Breastfeeding and long-chain polyunsaturated fatty 
acid intake in the first 4 post-natal months and infant cognitive development: an observational study. Matern Child Nutr. 2012;8(4):471-82.

3. Campos LN, Torrinhas RSMM, Antunes MS, Waitzberg DL. Gorduras. In: Waitzberg DL, ed. Nutrição oral, enteral e parenteral na prática clínica. $5^{\mathrm{a}}$ ed. Rio de Janeiro: Atheneu; 2017. p.135-59.

4. Nogueira-de-Almeida CA, Ribas Filho D, Mello ED, Bertolucci PHF, Falcão MC. I Consenso da Associação Brasileira de Nutrologia sobre recomendações de DHA durante gestação, lactação e infância. Int J Nutrol. 2014. [cited 2020 Aug 1]. Available from: https://www.academia.edu/27224985/I_Consenso da_Associa\%C3\%A7\%C3\%A3o_Brasileira_de Nutrologia sobre recomenda $\% \mathrm{C} 3 \% \mathrm{~A} 7 \% \mathrm{C} 3 \% \mathrm{~B} 5 \mathrm{es}$ de $\mathrm{D} \overline{\mathrm{H}} \mathrm{A}$ durante gesta $\%$ C $3 \%$ A $7 \%$ C $3 \%$ A 30 lacta $\%$ C $3 \%$ A $\overline{7} \%$ C $3 \%$ A $30 \_$inf $\% \mathrm{C} 3 \% \mathrm{~A} 2$ ncia

5. Burdge GC. Metabolism of alpha-linolenic acid in humans. Prostaglandins Leukot Essent Fatty Acids. 2006;75(3):161-8.

6. Torrinhas R, Garla P, Silva J, Oliveira Filho R, Castro M, Waitzberg DL. Nutriente: óleo de peixe e ácidos graxos ômega 3. In: Waitzberg DL, ed. Nutrição oral, enteral e parenteral na prática clínica. $5^{\mathrm{a}}$ ed. Rio de Janeiro: Atheneu; 2017. p.2571-95.

7. Kayser CGR, Krepsky LH, Oliveira MR, Liberali R, Coutinho V. Benefícios da ingestão de ômega 3 e a prevenção de doenças crônico degenerativas: revisão sistemática. Rev Bras Obesidade, Nutrição e Emagrecimento. 2010;4(21):137-46.

8. Qawasmi A, Landeros-Weisenberger A, Bloch MH. Meta-analysis of LCPUFA supplementation of infant formula and visual acuity. Pediatrics. 2013;131(1):e262-72.

9. Makrides M, Collins CT, Gibson RA. Impact of fatty acid status on growth and neurobehavioral development in humans. Matern Child Nutr. 2011;7(Suppl 2):80-8.

10. Hadders-Algra M. Effect of long-chain polyunsaturated fatty acid supplementation on neurodevelopmental outcome in full-term infants. Nutrients. 2010;2(8):790-804.

11. Pinot M, Vanni S, Pagnotta S, Lacas-Gervais S, Payet LA, Ferreira $\mathrm{T}$, et al. Lipid cell biology. Polyunsaturated phospholipids facilitate membrane deformation and fission by endocytic proteins. Science. 2014;345(6197):693-7.

12. Innis SM. Dietary (n-3) fatty acids and brain development. J Nutr. 2007;137(4):855-9.

13. Colombo J, Carlson SE, Cheatham CL, Shaddy DJ, Kerling EH, Thodosoff JM, et al. Long-term effects of LCPUFA supplementation on childhood cognitive outcomes. Am J Clin Nutr. 2013;98(2):403-12.

14. Lassek WD, Gaulin SJ. Maternal milk DHA content predicts cognitive performance in a sample of 28 nations. Matern Child Nutr. 2015;11(4):773-9.

15. Birch EE, Khoury JC, Berseth CL, Castañeda YS, Couch JM, Bean J, et al. The impact of early nutrition on incidence of allergic manifestations and common respiratory illnesses in children. $\mathrm{J}$ Pediatr. 2010;156(6):902-6.

16. CalderPC.n-3 fattyacids, inflammationandimmunity:new mechanisms to explain old actions. Proc Nutr Soc. 2013;72(3):326-36.

17. Mickleborough TD, Ionescu AA, Rundell KW. Omega-3 fatty acids and airway hyperresponsiveness in asthma. JAltern Complement Med. 2004;10(6):1067-75.

18. Miyata J,Arita M. Role of omega-3 fatty acids and their metabolites in asthma and allergic diseases. Allergol Int. 2015;64(1):27-34.

19. Costantini L, Molinari R, Farinon B, Merendino N. Impact of omega-3 fatty acids on the gut microbiota. Int J Mol Sci. 2017;18(12):2645

20. American Academy of Pediatrics. Formula feeding of term infants. In: Kleinman RE, American Academy of Pediatrics, Committee on Nutrition, eds. Pediatric nutrition handbook. 6th ed. Elk Grove Village: American Academy of Pediatrics; 2009. p.61-78.
21. Silva DRB, Miranda Jr PF, Soares EA. A importância dos ácidos graxos poliinsaturados de cadeia longa na gestação e lactação. Rev Bras Saude Mater Infant. 2007;7(2):123-33.

22. Wijendran V, Huang MC, Diau GY, Boehm G, Nathanielsz PW, Brenna JT. Efficacy of dietary arachidonic acid provided as triglyceride or phospholipid as substrates for brain arachidonic acidaccretion in baboonneonates. Pediatr Res. 2002;51(3):265-72.

23. Liu L, Bartke N, Van Daele H, Lawrence P, Qin X, Park HG, et al. Higher efficacy of dietary DHA provided as a phospholipid than as a triglyceride for brain DHA accretion in neonatal piglets. J Lipid Res. 2014;55(3):531-9.

24. Graf BA, Duchateau GS, Patterson AB, Mitchell ES, van Bruggen $\mathrm{P}$, Koek JH, et al. Age dependent incorporation of 14C-DHA into rat brain and body tissues after dosing various 14C-DHA-esters. Prostaglandins Leukot Essent Fatty Acids. 2010;83(2):89-96.

25. Innis SM. Metabolic programming of long-term outcomes due to fatty acid nutrition in early life. Matern Child Nutr. 2011;7(Suppl 2):112-23.

26. Willatts P, Forsyth JS, DiModugno MK, Varma S, Colvin M. Effect of long-chain polyunsaturated fatty acids in infant formula on problem solving at 10 months of age. Lancet. 1998;352(9129):688-91.

27. Willatts P, Forsyth S, Agostoni C, Casaer P, Riva E, Boehm G. Effects of long-chain PUFA supplementation in infant formula on cognitive function in later childhood. Am J Clin Nutr. 2013;98(2):536S-42S.

28. Georgieff MK. Nutrition and the developing brain: nutrient priorities and measurement. Am J Clin Nutr. 2007;85(2):614S-20S.

29. Bouwstra H, Dijck-Brouwer DA, Wildeman JA, Tjoonk HM, van der Heide JC, Boersma ER, et al. Long-chain polyunsaturated fatty acids have a positive effect on the quality of general movements of healthy term infants. Am J Clin Nutr. 2003;78(2):313-8.

30. Müller M, Kersten S. Nutrigenomics: goals and strategies. Nat Rev Genet. 2003;4(4):315-22.

31. Araújo LA, Moretzsohn MA. Composição lipídica. In: International Life Sciences Institute do Brasil, editor. Dinâmica da composição do leite humano e suas implicações clínicas. volume 8. São Paulo: ILSI Brasil- International Life Sciences Institute do Brasil; 2018. p.29-41.

32. Calil VMLT, Vaz FAC. Composição bioquímica do leite humano. In: Issler $\mathrm{H}$, ed. $\mathrm{O}$ aleitamento materno no contexto atual. São Paulo: Sarvier; 2008. p.177-90.

33. Koo WW, Hockman EM, Dow M. Palm olein in the fat blend of infant formulas: effect on the intestinal absorption of calcium and fat, and bone mineralization. J Am Coll Nutr. 2006;25(2): 117-22.

34. Silva RC, Gioielli LA. Lipídios estruturados: alternativa para a produção de sucedâneos da gordura do leite humano. Quim Nova. 2009;32(5):1253-61.

35. Kus MMM, Silva SA, Aued-Pimentel S, Mancini Filho J. Nutrition facts of infant formulas sold in São Paulo state: assessment of fat and fatty acid contents. Rev Nutr. 2011;24(2):209-18.

36. Innis SM. Dietary triacylglycerol structure and its role in infant nutrition. Adv Nutr. 2011;2(3):275-83.

37. Nowacki J, Lee HC, Lien R, Shao-Wen Cheng, Sung-Tse Li, Manjiang Yao, et al. Stool fatty acid soaps, stool consistency and gastrointestinal tolerance in term infants fed infant formulas containing high sn-2 palmitate with or without oligofructose: a double-blind, randomized clinical trial. Nutr J. 2014;13:105.

38. Litmanovitz I, Davidson K, Eliakim A, Regev RH, Dolfin T, Arnon $\mathrm{S}$, et al. High beta-palmitate formula and bone strength in term infants: a randomized, double-blind, controlled trial. Calcif Tissue Int. 2013;92(1):35-41.

39. Yaron S, Shachar D, Abramas L, Riskin A, Bader D, Litmanovitz I, et al. Effect of high $\beta$-palmitate content in infant formula on the intestinal microbiota of term infants. J Pediatr Gastroenterol Nutr. 2013;56(4):376-81.

Local de realização do estudo: Instituto da Criança - HC-FMUSP, São Paulo, SP, Brasil.

Conflito de interesse: $\mathrm{O}$ autor presta ou prestou serviços de assessoria médico-científica para as seguintes empresas: Nestlé, Batavo, Mead Johnson Nutrition, DSM, Aché, Baxter, Exeltis, Naturalis e Danone. 